\title{
Análise do Desempenho Térmico em Habitações Populares Através da Simulação das Características dos Materiais Constituintes de sua Envoltória
}

\section{Analysis of Thermal Performance in Public Housing Through Simulation of Characteristics of Constituent Materials of his envelopment}

\author{
Raul Vitor Arantes Monteiro, Bismarck Castillo Carvalho e Fernando Nogueiria \\ Professores do Departamento de Engenharia Elétrica \\ Faculdade de Arquitetura, Engenharia e Tecnologia FAET/UFMT
}

\begin{abstract}
Enviado em setembro 2014: Aceito em setembro $2014 \quad$ Publicado em Novembro 2014
Resumo: A partir da década de 1980, observa-se no Brasil o fenômeno social conhecido como êxodo rural. Tal fenômeno consiste na migração de populações originárias do meio rural para as regiões urbanas. Esta situação trouxe como consequência direta, a demanda em massa por moradias, fato que se constitui em desafio para o poder público no sentido de suprir esta necessidade, levando à adoção de políticas públicas, com o objetivo de dar tratamento digno e saudável a todo esse contingente de pessoas, que passaram a fazer parte da população urbana do país. Com isto diversos programas habitacionais foram criados para tentar atender a esta demanda crescente como o mais famoso dentre eles o BNH (Banco Nacional de Habitação) que tinha por objetivo prover recursos financeiros para que a população adquirisse suas casas. Ao longo dos anos o que se pôde observar era que essas casas chamadas de habitações de interesse social, eram feitas através de projetos repetitivos empregados em várias regiões do Brasil sem levar em consideração o clima típico de cada região, o emprego dos materiais construtivos das habitações e, consequentemente sem levar em consideração o conforto ambiental dos habitantes nessas habitações. Este trabalho tem por objetivo fazer a análise para edificações destinadas a habitações de interesse social, horizontais e verticais através de simulações computacionais e através disso propor em quais condições esses tipos de edificações teriam melhor desempenho energético, servindo de sugestão para a construção futura de habitações desse porte.
\end{abstract}

Palavras-chave: Habitação popular. Conforto térmico. Envoltória.

\begin{abstract}
From the 1980s, we observe in Brazil the social phenomenon known as rural exodus. This phenomenon is the migration of populations originating from rural to urban areas. This situation brought as a direct consequence, the demand for mass housing, the fact that offering a challenge to the government in order to meet this need, leading to the adoption of public policies, with the objective of providing decent and healthy treatment to all this number of people who became part of the urban population of the country. With that many housing programs were created to try to meet this growing demand as the most famous among them $\mathrm{BNH}$ (National Housing Bank) which aimed to provide financial resources for the population to acquire their homes. Over the years what could be observed was that these houses called social housing, were made through repetitive designs employed in various regions of Brazil without taking into account the typical climate of each region, the use of building materials of dwellings and thus without taking into consideration the environmental comfort of the inhabitants in these dwellings. This work aims to do this analysis for buildings for the housing of horizontal and vertical social interest through computer simulations and thereby propose conditions in which these types of buildings would have better energy performance, serving suggestion for the future construction of homes of this size.
\end{abstract}

Keywords: Public housing. Thermal comfort. Envelope.

\section{Introdução}

Ao longo da história das políticas de habitações populares no Brasil, diferentes programas habitacionais tentaram suprir a necessidade de moradias e reduzir o déficit habitacional brasileiro. A qualidade dos projetos parece não estar dentro das preocupações desses programas. Posto a necessidade de oferecerem uma grande quantidade de moradias a baixo custo, projetos de áreas mínimas e padronização excessiva são frequentes. Nas plantas das unidades habitacionais é possível notar falhas graves de funcionalidade e a falta de flexibilidade, que dificulta a adaptação da casa pelas famílias beneficiadas, tanto no 
momento da entrada, quanto ao longo do tempo de uso.

Especialistas criticam o enfoque que o Estatuto da Cidade atribui à HIS, que parece ter como único objetivo oferecer um teto com o menor custo possível. Argumentam que o espaço habitacional acaba sendo medido ao invés de pensado, e o resultado que se tem é a constante miniaturização, homogeneização e massificação da produção. Tal fato dificulta uma melhor relação entre o morador e sua habitação, e entre esta e a cidade, inexistindo uma relação de pertencimento e integração ao ambiente urbano, perdendo assim a nobre função de inclusão social. Alguns especialistas defendem que, para que a HIS cumpra sua função, ela não pode se restringir apenas à unidade habitacional (UH). Assim, além de conter um espaço confortável, seguro e salubre, é necessário que a habitação seja considerada de forma mais abrangente, incorporando infraestrutura, serviços urbanos e equipamentos sociais.

Muitos são os estudos sobre a qualidade do projeto habitacional. Alguns tratam de seu desempenho técnico, outros de seu processo produtivo, e poucos tratam de seu desempenho como um todo. Questões sobre a qualidade dos materiais que constituem as envoltórias dessas edificações são pouco tratadas senão completamente esquecidas.

\section{Revisão Bibliográfica}

O conforto térmico é definido como uma condição mental que expressa satisfação com o ambiente térmico circunjacente (que jaz a volta, circunvizinho). Ter conforto térmico significa que uma pessoa usando uma quantidade normal de roupas não sente nem frio nem calor demais.

Um dos fatores elementares que influenciam a qualidade do trabalho dos trabalhadores é a condição de conforto térmico com que são submetidos no seu ambiente de trabalho, influenciando diretamente no seu desempenho e rendimento.
Dentre as várias variáveis o calor produzido depende do tipo de atividade que o indivíduo vem realizando, e o calor perdido principalmente da sua vestimenta, havendo a necessidade de conhecimento do clima, conhecimento dos mecanismos de trocas de calor e conhecimento sobre comportamento térmico dos materiais para se realizar um estudo de conforto térmico.

$\mathrm{O}$ desconforto térmico esta relacionado ao fluxo sanguíneo da camada periférica do corpo, a camada subcutânea. Dois são os fenômenos do fluxo sanguíneo: a vasodilatação e vasoconstrição, reduzindo ou aumentando a resistência térmica dessa camada subcutânea.

Nos últimos anos o desenvolvimento tecnológico e a descoberta de novos materiais têm contribuído para que o ato de construir e projetar se desvincule do ambiente natural, pois o clima local e os materiais disponíveis na região já não são devidamente levados em consideração na fase de projeto, o que leva a projetos com baixos índices de conforto térmico e em consequência a um elevado consumo de energia para condicionar artificialmente ambientes.

Outro ponto importante na análise do desempenho térmico das edificações diz respeito à orientação solar das fachadas, pois cada face da envoltória da edificação recebe o calor do sol de forma diferente. $\mathrm{O}$ sol ao penetrar pelas aberturas ou atravessar materiais transparentes pode ocasionar, dentro outros fatores, ofuscamento, aquecimento de moveis, equipamentos ou causar desbotamento de tapetes e quadros (FROTA, 2001).

A orientação em função da radiação térmica está associada à latitude do local onde é implantado o edifício. Segundo Frota e Schiffer (2001, p. 84) quanto maior for a latitude do local menor será a quantidade de radiação solar recebida e consequentemente as temperaturas tenderão a ser menores. À medida que diminui a latitude, a orientação em função da radiação solar passa a ser um fator secundário nas medidas de racionalização do uso da energia. Já a orientação do edifício em função dos ventos 
dominantes favoráveis é fundamental para a obtenção de conforto e economia de energia (MASCARÓ, 1986).

\section{Energy Plus}

As simulações computacionais têm sido de grande valor na avaliação de projetos de edificações, pois, na medida em que a capacidade de processamento dos computadores evolui, o trabalho conjunto de grande quantidade de variáveis aumenta.

Segundo Hensen, Lamberts e Negrão (2002), o desenvolvimento, avaliação, uso em prática e padronização de modelos e programas são de importância crescente, e a integração de métodos e ferramentas é necessária.

Algumas entidades se destacam na disseminação do conhecimento sobre simulações, tais como a International Bulding Performance Simulation Association (IBPSA), Lawrence Berkeley National Laboratory (LBNL), e o Laboratório de Eficiência Energética em Edificações (LABEEE) da Universidade Federal de Santa Catarina (UFSC).

Segundo Inatomi (2008):

“A simulação computacional colabora
na tomada de decisões por
possibilitarem análises, em condições
transientes, de possíveis respostas das
edificações nos quesitos conforto do
usuário e eficiência energética em
função de variáveis relativas a:
materiais de construção, ocupação,
utilização do edifício, equipamentos,
sistemas de iluminação, sistemas de
energia renovável, sistemas de
condicionamento de ar, sistemas de
controle, clima local, projeto de
arquitetura e tarifação de energia."

O Energy Plus é um programa de simulação de carga térmica e análise de energia, que permite calcular as cargas de aquecimento e arrefecimento necessárias para manter os ajustes de controle térmico da(s) zona(s) em análises. Para tal, é necessário introduzir dados de entrada a geometria da zona a ser simulada. Dá-se o nome de zonas aos ambientes a serem simulados no EnergyPlus.

\section{Materiais e Métodos}

Para a realização deste trabalho, primeiramente foram feitas pesquisas para definir quais edificações se enquadrariam a esta proposta. Assim para a habitação popular horizontal foi escolhido $\mathrm{o}$ residencial Cláudio Marchetti e para a habitação popular vertical foi escolhido o condomínio Água Marinha. As descrições de ambas as habitações estão contidas na seção.

Após colher os projetos de ambas as habitações os mesmos tiveram que ser adaptados e assim foram refeitos para que fosse possível colocá-los neste trabalho. Em seguida estes projetos foram refeitos no software EnergyPlus, software este responsável por fazer as simulações das substituições dos materiais componentes das envoltórias das habitações a serem estudadas. Para estas simulações foi necessário o uso da NBR - 15220 Desempenho Térmico de Edificações, que nos informou os valores das grandezas que descrevem as características térmicas de materiais, elementos e componentes construtivos.

Para a visualização das habitações objetos deste estudo, foi utilizado o software Google Sketchup. As temperaturas que compõem o banco de dados do EnergyPlus são datadas de 1977 a 1998, ou seja, 20 anos. Este banco de dados foi alimentado pela SWERA. O SWERA disponibiliza gratuitamente, on - line, a base de dados climática necessárias para alimentar o banco de dados do EnergyPlus para o distrito climático de Cuiabá - MT, através dados inseridos em conjunto com o INPE (Instituto Nacional de Pesquisas Espaciais Brasil).

\section{Edificações Avaliadas}

O levantamento de projetos incluindo localizações, plantas de situação e planta baixa foram necessárias para a avaliação do 
desempenho térmico das habitações populares horizontais e verticais.

Para a análise do conforto térmico em habitação popular horizontal, foi escolhido o residencial Cláudio Marchetti, com área total construída de 43,96 $\mathrm{m}^{2}$ e $61,33 \mathrm{~m}^{2}$ de área coberta, situado à Avenida das Torres após o bairro jardim Imperial no município de Cuiabá - MT. A Figura 1 ilustra o residencial e na Tabela 1 apresentam - se os materiais que compõem a envoltória da habitação popular horizontal.

Figura 1 - Planta baixa e fachada da edificação horizontal.
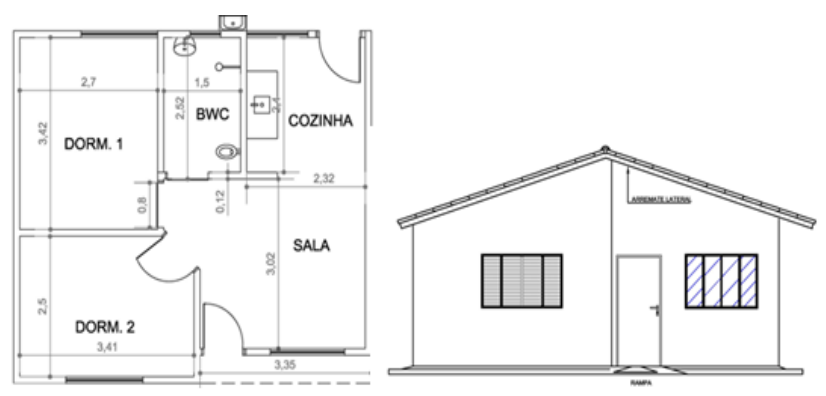

Fonte: Caixa Econômica Federal

Tabela 1 - Materiais constituintes da envoltória da edificação horizontal

\begin{tabular}{lll}
\hline Paredes & Cobertura & Piso \\
Tinta branca & $\begin{array}{l}\text { Telhas de } \\
\text { cerâmica }\end{array}$ & $\begin{array}{l}\text { Radier de } \\
\text { concreto }\end{array}$ \\
Argamassa & $\begin{array}{l}\text { Estrutura de } \\
\text { madeira }\end{array}$ & $\begin{array}{l}\text { Piso de } \\
\text { cerâmica }\end{array}$ \\
Tijolos 8 furos & & \\
Argamassa & & \\
Tinta branca & & \\
\hline
\end{tabular}

Para a análise do conforto térmico de uma habitação popular vertical foi escolhido o residencial Água Marinha com área total construída por apartamento de 54,39 $\mathrm{m}^{2}, 4$ andares, 4 apartamentos por andar, constituído de 6 blocos iguais, localizado à rua $A$, bairro Terra Nova, município de Cuiabá - MT, Figura 2. Os materiais que compõem sua envoltória se apresentam na Tabela 2.
Figura 2 - Planta baixa e fachada da habitação popular vertical.
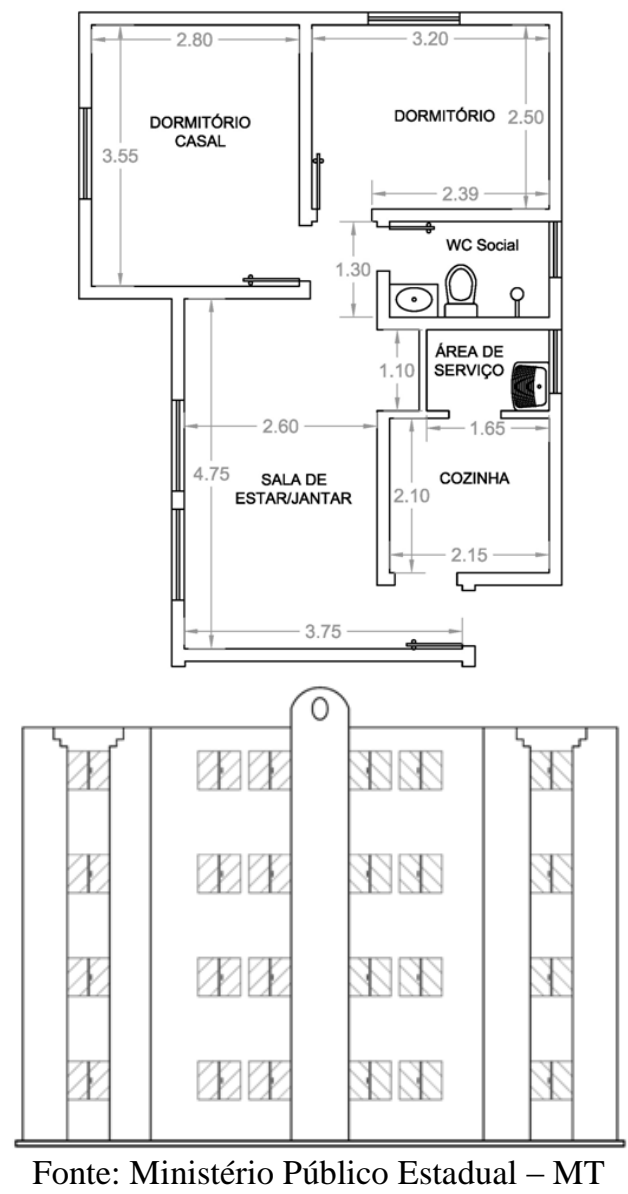

Tabela 2 - Materiais constituintes da envoltória da edificação vertical

\begin{tabular}{|c|c|c|}
\hline Paredes & Cobertura & Piso \\
\hline Tinta branca & $\begin{array}{l}\text { Laje de concreto } \\
10 \mathrm{~cm} \text { (entre } \\
\text { andares) }\end{array}$ & $\begin{array}{l}\text { Radier de } \\
\text { concreto }\end{array}$ \\
\hline Argamassa & & $\begin{array}{l}\text { Piso de } \\
\text { cerâmica }\end{array}$ \\
\hline \multicolumn{3}{|l|}{$\begin{array}{l}\text { Tijolos } 8 \\
\text { furos }\end{array}$} \\
\hline \multicolumn{3}{|l|}{ Argamassa } \\
\hline Tinta branca & & \\
\hline
\end{tabular}

\section{Simulações}

Para as simulações utilizaremos o RTQ - R, que enquadra o município de Cuiabá - MT como pertencente à zona bioclimática 7 . Esta definição é importante, pois define os níveis admissíveis de transmitância térmica e capacidade térmica para os materiais a serem empregados na envoltória das edificações para um bom conforto térmico. 
Para a habitação popular horizontal foi analisado o conforto térmico no ambiente sala e cozinha da edificação sendo analisados também à posição da habitação popular em relação ao sol, sendo uma com sua fachada orientada para nordeste (1) e outra com sua fachada orientada ao sudeste (3), conforme ilustra a Figura 3.

Figura 3 - Orientação das habitações populares horizontais analisadas.

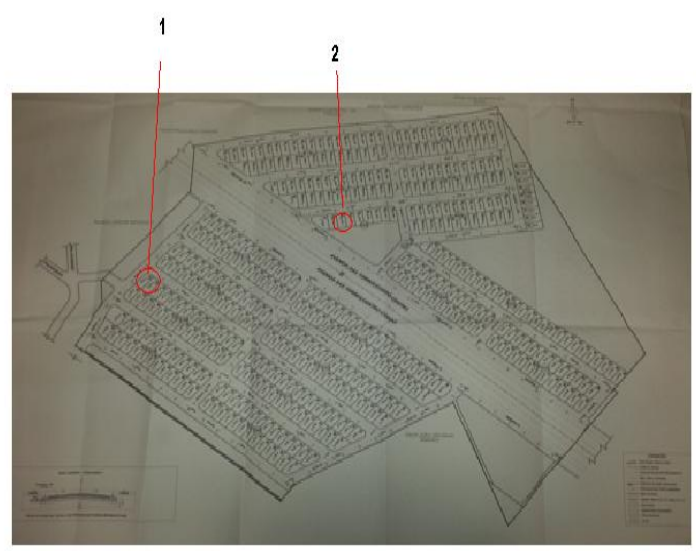

Para a habitação popular vertical, foi analisado o conforto térmico em todo o apartamento com sua posição original (4) e (5) com fachada orientada à leste e oeste, e em seguida com sua fachada orientada a norte e sul (6) com a melhor composição de materiais identificados nas simulações que garantiu $o$ melhor conforto térmico na habitação, conforme ilustra a Figura 4.

Figura 4 - Orientação dos HIS verticais analisados.

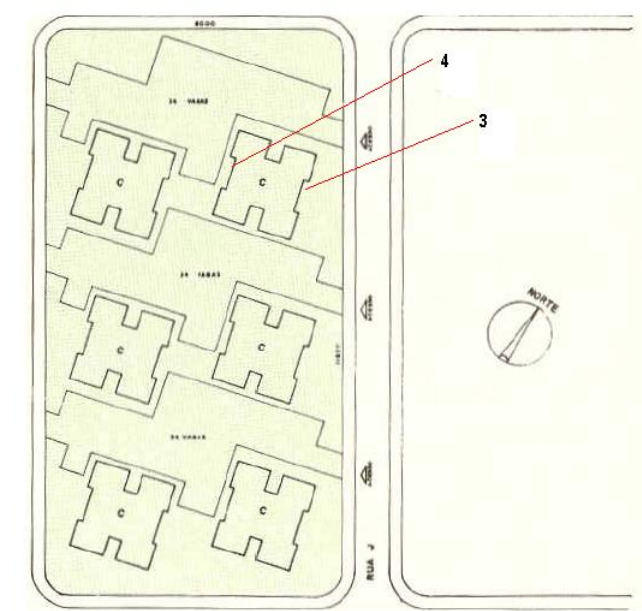

Fonte: Ministério Público Estadual - MT.
A Figura 5 ilustra as habitações no software Google Sketchup, software que dá suporte ao EnergyPlus para ilustrar e simular as edificações que o projetista deseja simular.

Figura 5 - Representação da habitação popular horizontal e vertical no software Google Sketchup.

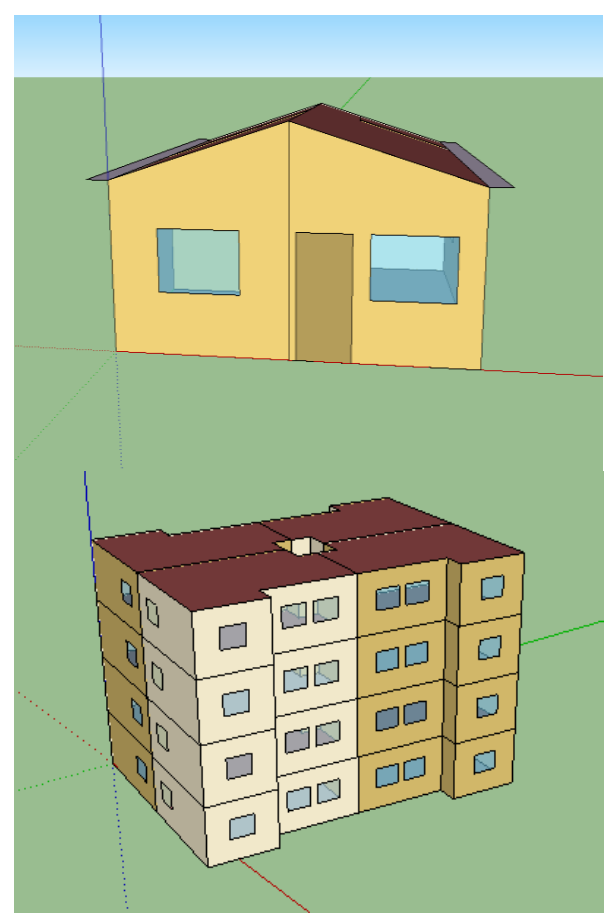

\section{Materiais Empregados nas Implementações Computacionais}

Para as simulações foram utilizadas composições de materiais empregados nas edificações em análise e em um segundo momento materiais que a NBR 15220 qualifica como sendo ideais para a zona bioclimática 7. Esta norma diz que a transmitância térmica (U) das paredes externas das edificações nesta zona bioclimática não deve ser superior a 2,5 $\mathrm{W} /\left(\mathrm{m}^{2} . \mathrm{K}\right)$ para ambientes não refrigerados artificialmente e para as coberturas (no caso das HIS horizontais) a transmitância térmica não deve ser superior a 2,0 $\mathrm{W} /\left(\mathrm{m}^{2} . \mathrm{K}\right)$ para edificações que não possuem refrigeração artificial. Na Tabela 3 ilustram - se os materiais utilizados nas simulações. 
Tabela 3 - Tipo de material, transmitância térmica, ordem da simulação e ilustração da composição dos materiais.

\section{Cobertura com telha de barro sem forro \\ Cobertura com telha de barro com \\ espessura de $1,0 \mathrm{~cm}$ sem forro}

Parede de tijolos de 8 furos circulares, assentados na menor dimensão. Dimensões do tijolo: 10,0x20,0x20,0 $\mathrm{cm}$. Espessura da argamassa de assentamento: 1,0 cm. Espessura da argamassa de emboço: 2,5 cm. Espessura total da parede: $15,0 \mathrm{~cm}$

Parede de tijolos de 6 furos circulares, assentados na menor dimensão.

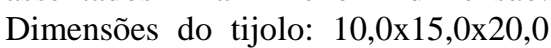
$\mathrm{cm}$. Espessura da argamassa de assentamento: $1,0 \mathrm{~cm}$

Espessura da argamassa de emboço: $2,5 \mathrm{~cm}$. Espessura total da parede: 15,0 $\mathrm{cm}$

Parede de tijolos de 8 furos circulares, assentados na maior

Dimensão Dimensões do tijolo: 10,0x20,0x20,0

$\mathrm{cm}$. Espessura da argamassa de assentamento: $1,0 \mathrm{~cm}$

Espessura da argamassa de emboço: $2,5 \mathrm{~cm}$

Espessura total da parede: $25,0 \mathrm{~cm}$

Parede de tijolos de 6 furos circulares, assentados na maior dimensão. Dimensões do tijolo: 10,0x15,0x20,0 $\mathrm{cm}$. Espessura da argamassa de assentamento: $1,0 \mathrm{~cm}$

Espessura da argamassa de emboço: $2,5 \mathrm{~cm}$. Espessura total da parede: 20,0 $\mathrm{cm}$

Fonte: NBR - 15220 parte 3

Para a cobertura de telha de barro com forro de madeira, conforme a NBR 15220, a transmitância térmica será de $2,0 \mathrm{~W} /\left(\mathrm{m}^{2} . \mathrm{K}\right)$. A ordem das simulações segue a mesma da tabela anterior apresentada, relacionadas aos mesmos materiais, porém começando pelo número 1.2.1, tendo assim 1.2.1, 1.2.2, 1.2.3, 1.2.4 simulações.

Para as simulações da edificação 2 , a simulação será 2.2.3, fazendo referência à simulação 1.2.3.

\section{Transmitância térmica Simulação $\mathbf{U}\left[\mathbf{W} /\left(\mathbf{m}^{2} . \mathbf{K}\right)\right]$ \\ 4,55 \\ (1) \\ 1 \\ 1}

2,24

1.1

Ilustração

\section{Hustrac}

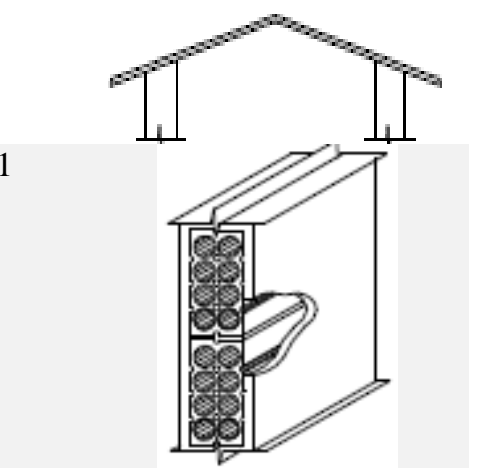

2,28

1.2

1,61

1.3

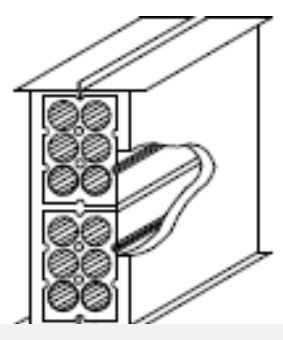

1,92

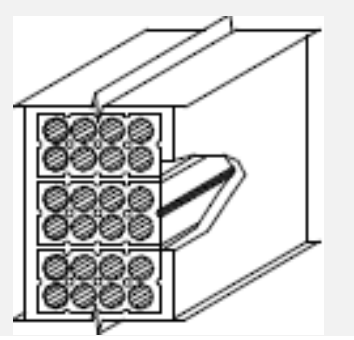

1.4

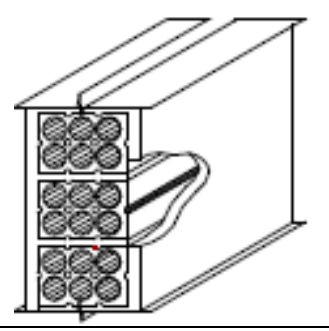

Para o edifício vertical foram utilizados os mesmos materiais, porém para a laje entre andares utilizou - se transmitância térmica de $1,75 \mathrm{~W} /\left(\mathrm{m}^{2} . \mathrm{K}\right)$ e a ordem das simulações para o apartamento número do lado numerado como 3 ficaram: unidade 203 3.1 e 203 - 3.1.3; unidade $403-3.1$ e $403-$ 3.1.3, seguindo a mesma ordem do quadro 3.

Para os apartamentos numerados para o lado 4, conforme figura 4, seguiu - se a mesma ordem: unidade $201-3.1$ e $201-$ 3.1.3; unidade $401-3.1$ e $401-3.1 .3$ 
Buscando a validação do banco de dados fornecido pelo SWERA, foram levantados dados climáticos para o município de Cuiabá - MT, para os anos de janeiro de 2010 até agosto de 2012, figuras 6 e 7, e conclui-se que as médias das temperaturas máximas e mínimas condizem com as informações fornecidas pelo SWERA, Figura 8.

Figura 2 - Médias de temperaturas para o ano de 2010 e 2011 em Cuiabá - MT.

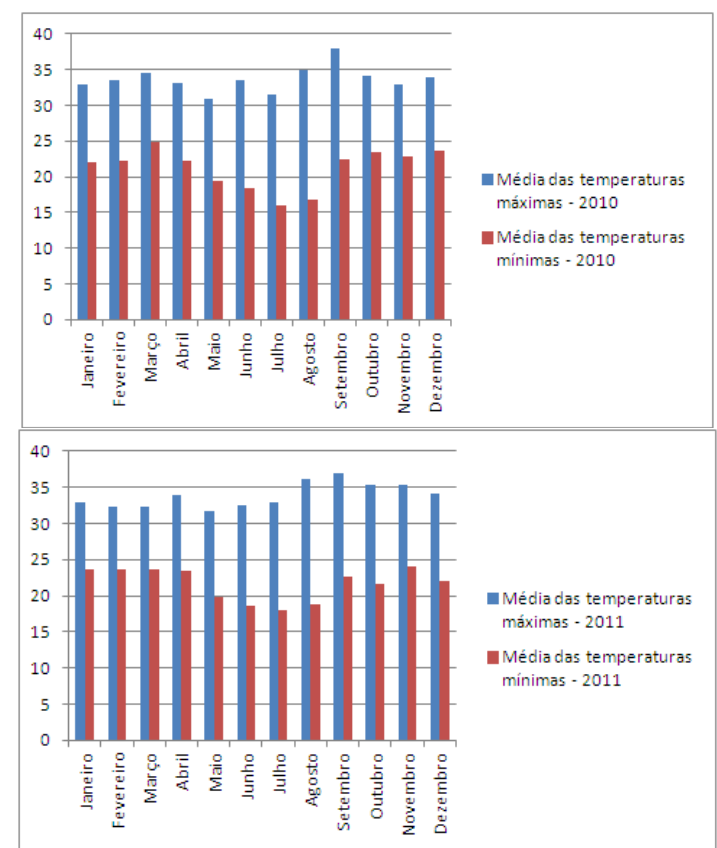

Fonte: Ministério da agricultura.

Figura 3 - Médias de temperaturas para o ano de 2012 em Cuiabá - MT.

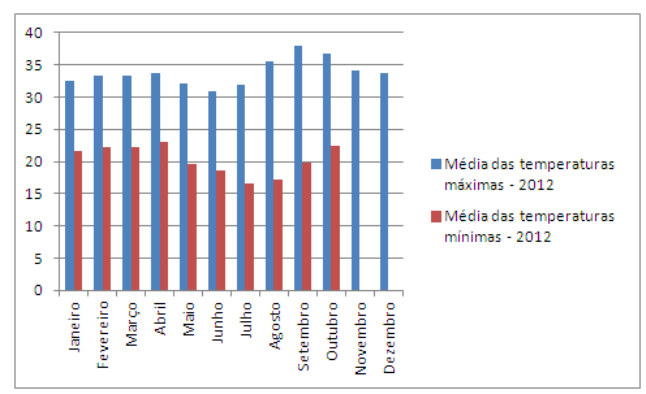

Fonte: Ministério da agricultura.
Figura 8 - Médias de temperaturas para o EnergyPlus.

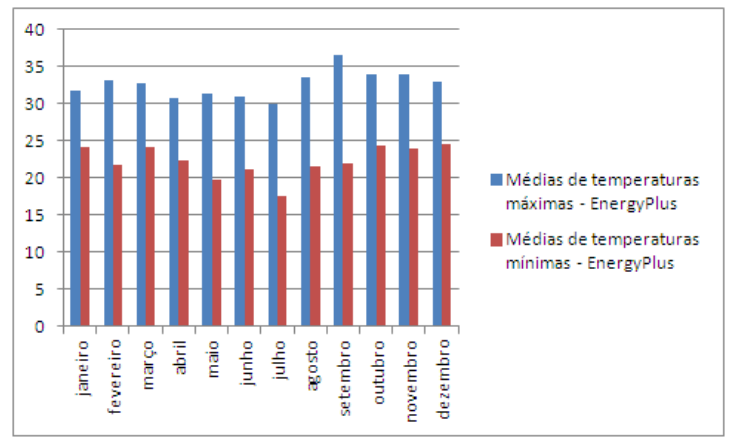

\section{Resultados das Simulações}

Nos meses com as menores temperaturas do ano, inverno, Figura 9, obteve-se uma melhor conservação da temperatura interior da edificação para as simulações $1.3 \mathrm{e}$ 1.2.3, sendo 1.2.3 (simulação com cobertura de telha de barro com forro de madeira) a que representou melhor desempenho térmico neste sentido.

Por outro lado quando analisados os dados dos meses com as maiores temperaturas do ano, primavera, obteve-se uma diferença de temperatura de quase $0,5^{\circ} \mathrm{C}$ para a melhor composição de materiais resultante das simulações entre 1.3 e 1.2.3, figura 10 , sendo a 1.2.3 a que representou melhor desempenho térmico. 
Citação: Monteiro R. V. A., Carvalho B. C., Nogueira F. Análise do Desempenho Térmico em Habitações Populares Através da Simulação das Características dos Materiais Constituintes de Sua Envoltória. E\&S - Engineering and Science, (2014), 2:1.

Figura 9 - Temperaturas obtidas por simulação para os meses de inverno com diversos materiais constituindo envoltória da edificação horizontal
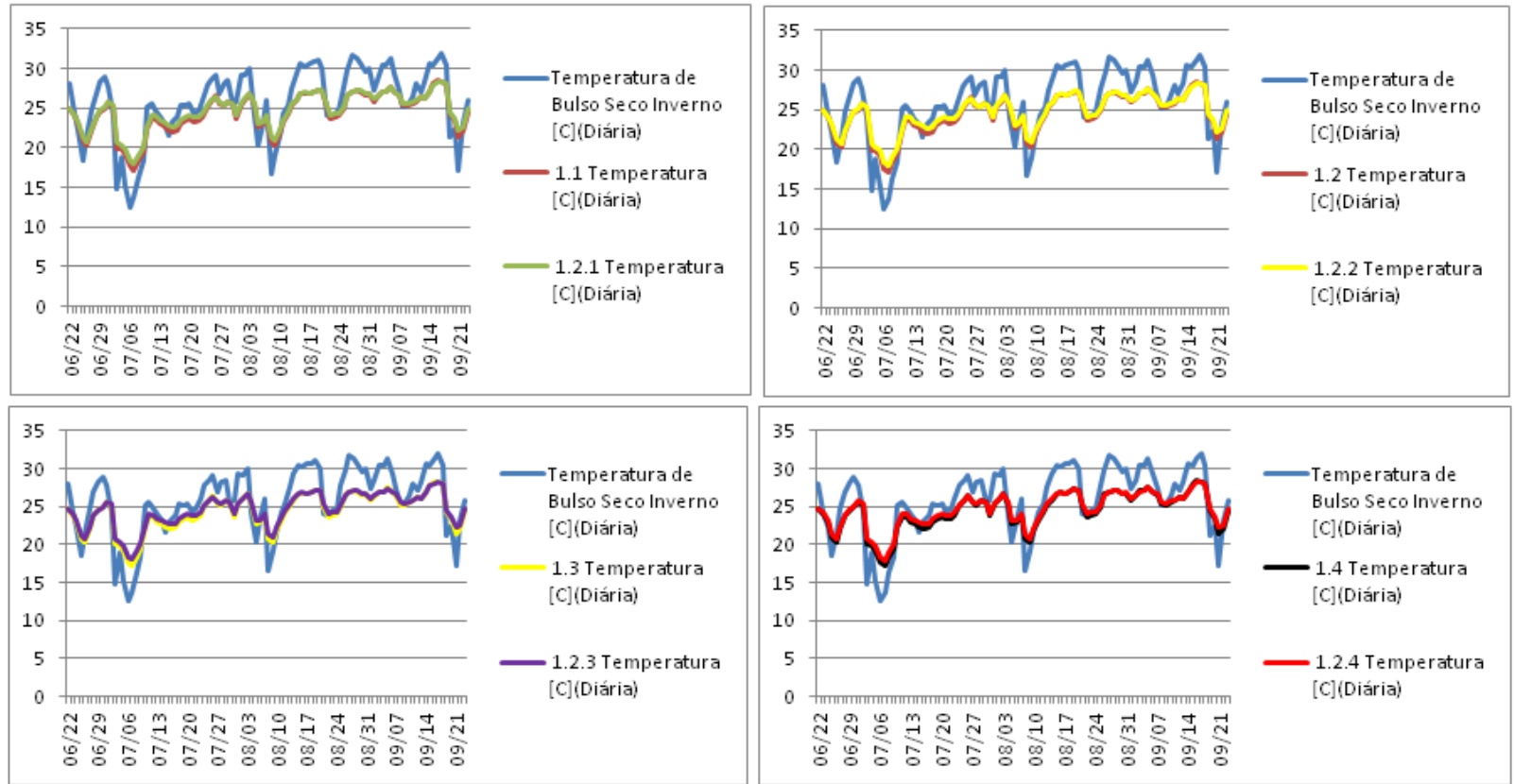

Figura 10 - Temperaturas obtidas por simulação para os meses de primavera com diversos materiais constituindo a envoltória da edificação horizontal.
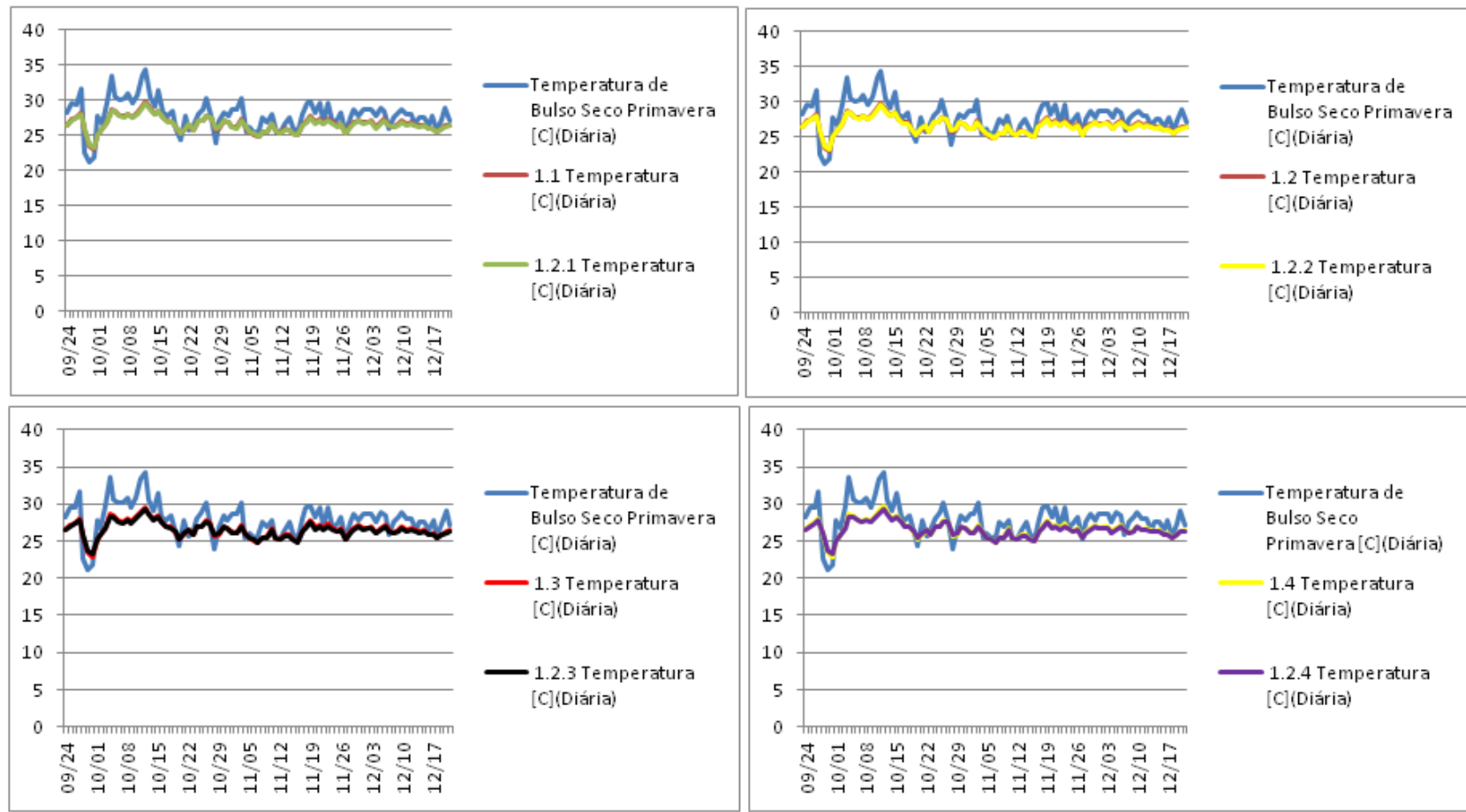

Obteve-se ainda uma diferença de quase $1{ }^{\circ} \mathrm{C}$ nos cômodos em análise (sala e cozinha) da edificação horizontal entre a simulação que compunha os materiais da construção original da edificação (simulação 1.1) e a melhor opção com cobertura com forro de maior dimensão (simulação 1.2.3). Para esta simulação foram plotados os gráficos para a estação mais quente do ano, primavera e, para a mais fria do ano, inverno, ilustrados nos gráficos das Figuras 11 e 12 respectivamente. madeira e tijolo 8 furos assentado em sua 
Citação: Monteiro R. V. A., Carvalho B. C., Nogueira F. Análise do Desempenho Térmico em Habitações Populares Através da Simulação das Características dos Materiais Constituintes de Sua Envoltória. E\&S - Engineering and Science, (2014), 2:1.

Figura 11 - Temperaturas obtidas por simulação no interior da edificação horizontal com materiais da sua construção original e a melhor opção de composição analisada para os meses de primavera

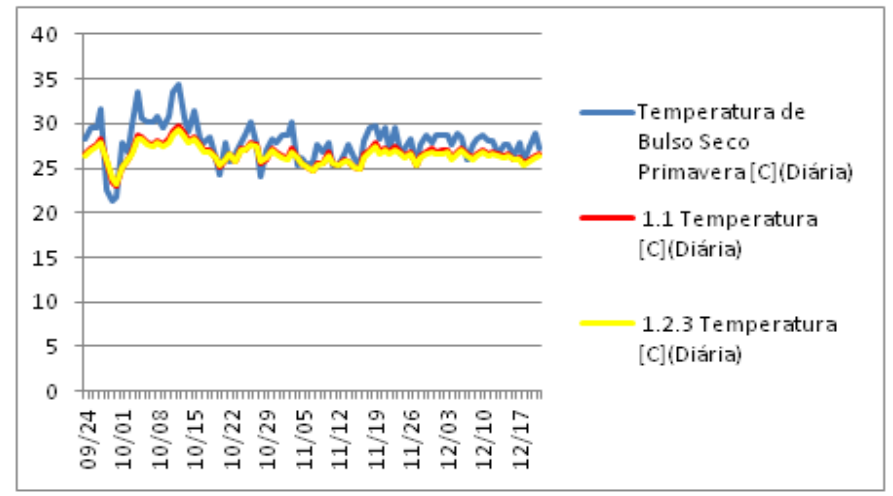

Figura 42 - Temperaturas obtidas por simulação no interior da edificação horizontal com materiais da sua construção original e a melhor opção de composição analisada para os meses de inverno.

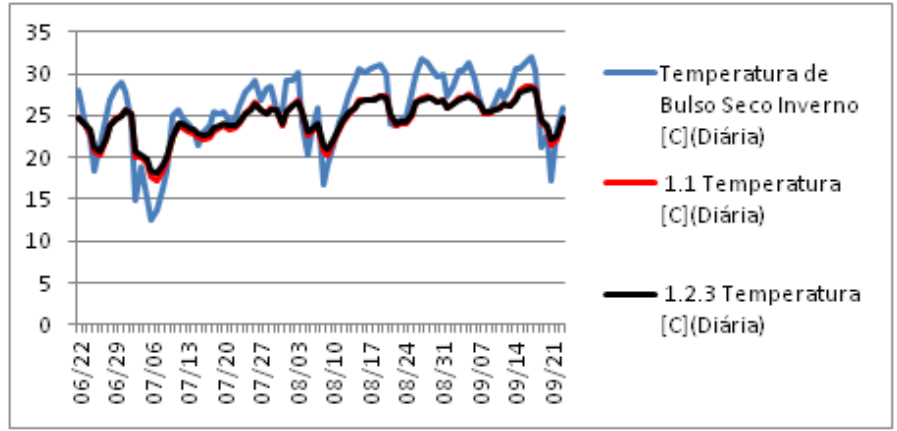

Como resultado da melhor composição de materiais e cobertura, utilizaremos a em relação ao sol (3) sendo 2.2.3 as composição utilizada na simulação 2.3 para a simulações pertencentes a esta situação, edificação horizontal com orientação diferente Figuras 13 e 14.

Figura 13 - Temperaturas obtidas por simulação no interior da edificação horizontal com diferentes orientações da sua fachada em relação ao sol, com a melhor opção de composição de materiais analisada para os meses de primavera.

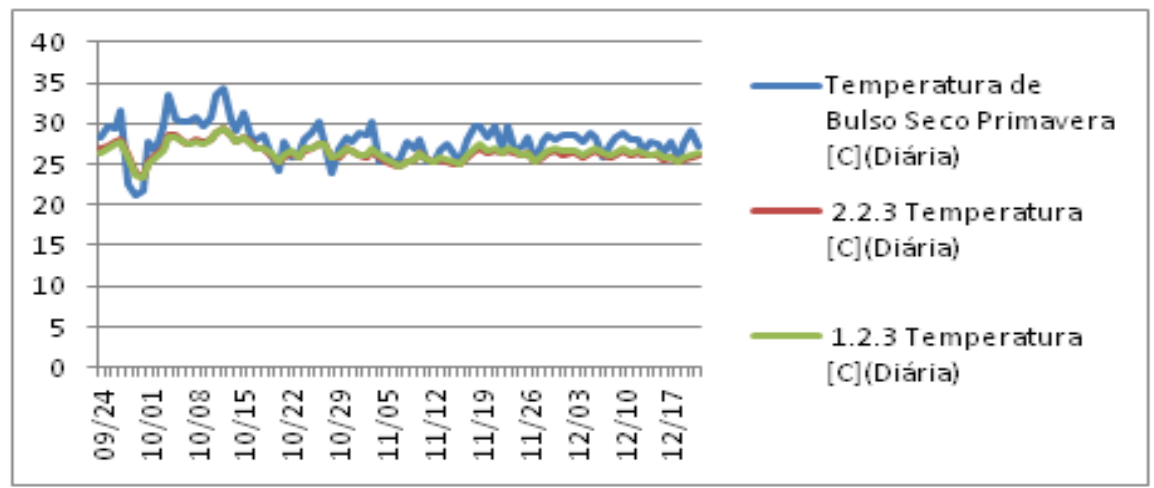


Citação: Monteiro R. V. A., Carvalho B. C., Nogueira F. Análise do Desempenho Térmico em Habitações Populares Através da Simulação das Características dos Materiais Constituintes de Sua Envoltória. E\&S - Engineering and Science, (2014), 2:1.

Figura 14 - Temperaturas obtidas por simulação no interior da edificação horizontal com diferentes orientações da sua fachada em relação ao sol, com a melhor opção de composição de materiais analisada para os meses de inverno.

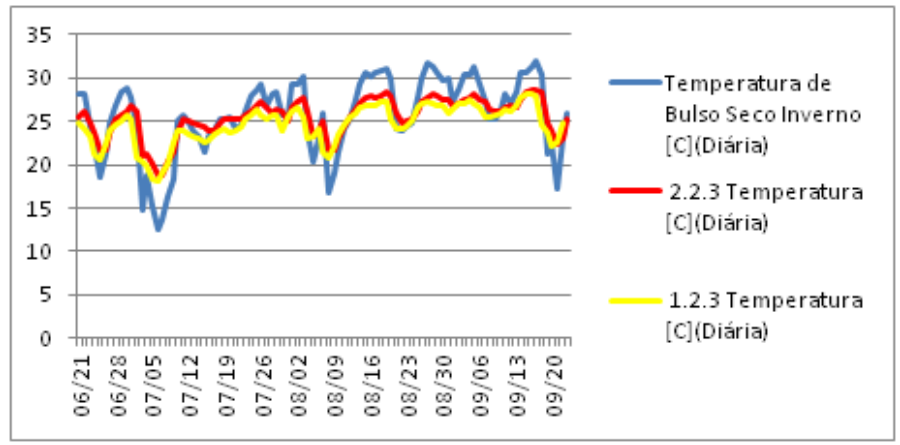

Através desses gráficos obteve-se que a orientação da fachada da edificação (2), sudeste, em relação ao sol, para os cômodos em análise (sala e cozinha) é mais confortável termicamente do que a edificação (1) que tem fachada orientada a nordeste. Para os materiais que compõem a melhor opção da envoltória e cobertura, obteve-se uma diferença de quase $0,4^{\circ} \mathrm{C}$ no interior dos cômodos analisados para os meses com maior e menor temperatura, modificando apenas a orientação da edificação, o que resulta em uma diferença de quase $1,4^{\circ} \mathrm{C}$ comparando a edificação com melhor orientação em relação ao sol (nordeste) e materiais (simulação 2.2.3) com sua pior composição de materiais da envoltória (materiais originais da construção simulação 1.1).

Resultados das simulações para as edificações verticais

Para as simulações dos apartamentos que constituem a edificação vertical, serão simulados somente os meses que compõem as estações mais quentes e frias do ano, ou seja, primavera e inverno respectivamente.

Será simulada também, somente a composição com os melhores materiais que constituíram a envoltória das edificações horizontais simulados anteriormente (tijolo 8 furos redondos de cerâmica assentados em sua maior dimensão). Isto se justifica devido ao fato de que os materiais que compõem originalmente essas edificações são os mesmos, conforme apresentados nos quadros 3 e 4 .
As primeiras simulações feitas são relativas ao edifício em sua orientação original. Os apartamentos escolhidos para a primeira análise foram um intermediário (unidade 203) e um superior (unidade 403) orientados ao leste e, um apartamento intermediário (unidade 201) com um superior (unidade 401) orientado à oeste em relação ao nascer do sol.

Através dos gráficos é possível analisar uma pequena diferença de temperatura, de aproximadamente $0,2^{\circ} \mathrm{C}$ entre apartamentos com mesma orientação em relação ao sol, por exemplo, os apartamentos 201 e 401, Figuras 15 e 16. Ainda nestes gráficos se observa, através dos dados coletados das simulações, uma diferença de temperatura de $0,4^{\circ} \mathrm{C}$ entre os apartamentos orientados a oeste e os apartamentos orientados a leste que se situam nos andares intermediários (201 e 203), sendo os orientados a oeste apresentando menor ganho térmicos. Os apartamentos 401 e 403 apresentaram mesma temperatura e ganho térmico interno.

Assim como nas edificações horizontais, nota-se uma diferença de aproximadamente

$0,3^{\circ} \mathrm{C}$ de temperatura quando trocamos os materiais componentes da envoltória da construção original, figuras 17 e 18 .

Essa diferença é menor quando comparada a troca dos mesmos materiais da edificação horizontal, pois, na mesma foi feita a troca do forro da cobertura, o que resultou essa diferença. 
Citação: Monteiro R. V. A., Carvalho B. C., Nogueira F. Análise do Desempenho Térmico em Habitações Populares Através da Simulação das Características dos Materiais Constituintes de Sua Envoltória. E\&S - Engineering and Science, (2014), 2:1.

Figura 15 - Temperaturas obtidas por simulação interna de apartamentos em diferentes pavimentos e diferentes orientações para os meses de primavera com a melhor composição de materiais analisada.

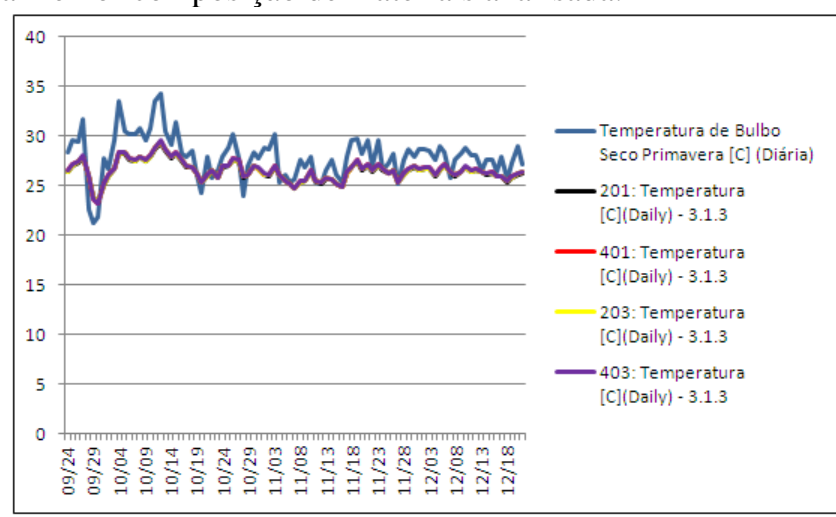

Figura 16 - Temperaturas obtidas por simulação interna de apartamentos em diferentes pavimentos e diferentes orientações para os meses de primavera com a melhor composição de materiais analisada.

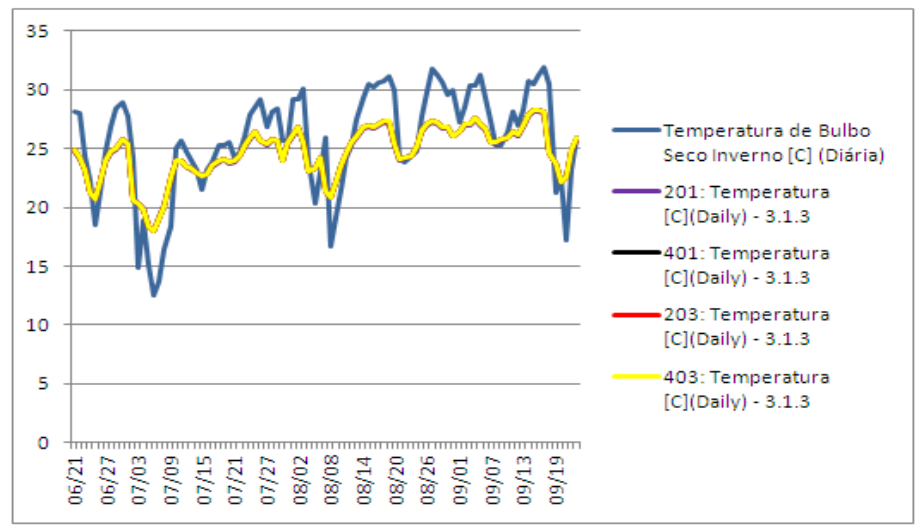

Figura 17 - Temperaturas obtidas por simulação entre os mesmos apartamentos com materiais originais de suas construções e a melhor composição encontrada de materiais das envoltórias. Meses de primavera.

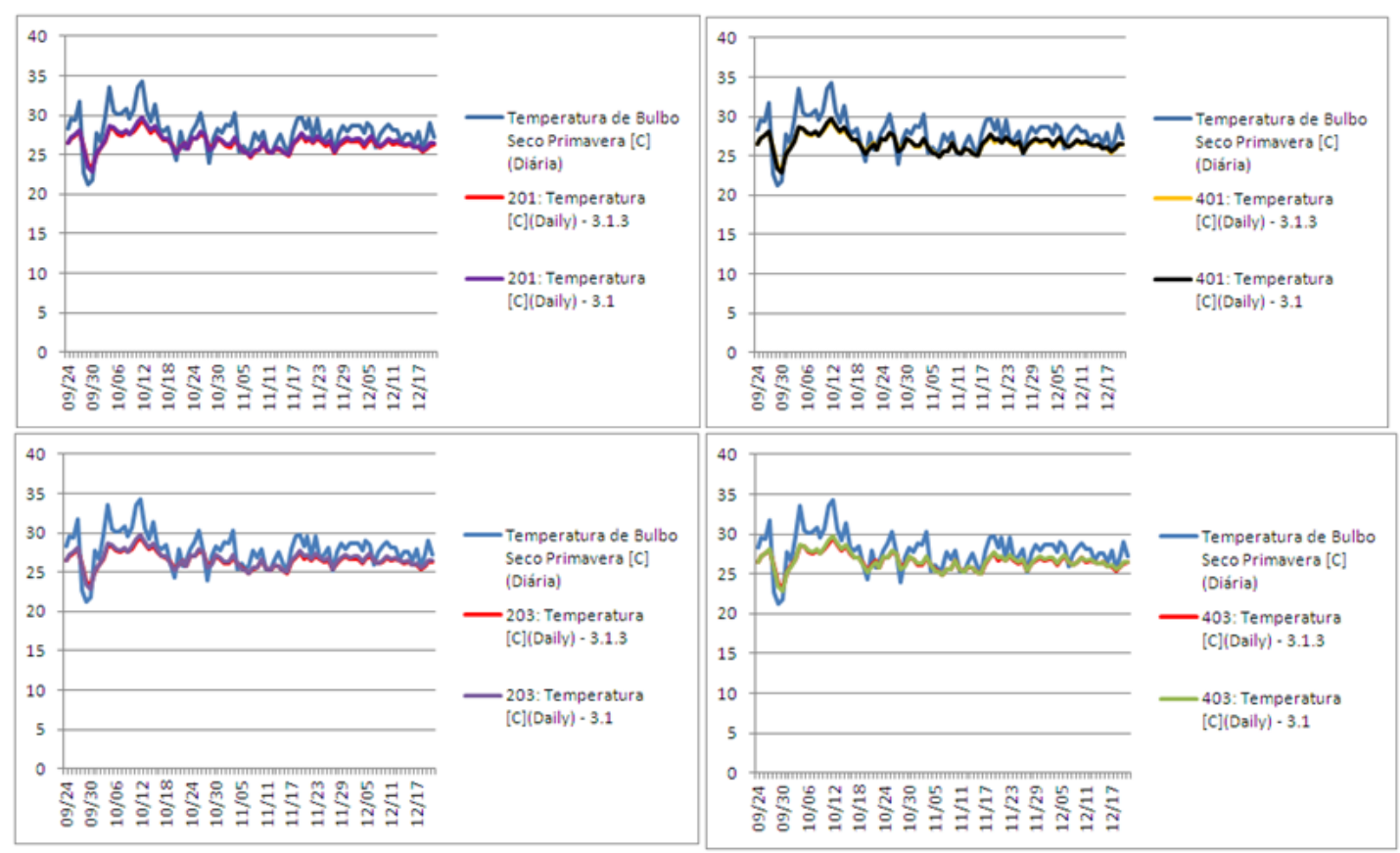


Figura 185 - Temperaturas obtidas por simulação entre os mesmos apartamentos com materiais originais de suas construções e a melhor composição encontrada de materiais das envoltórias. Meses de inverno.

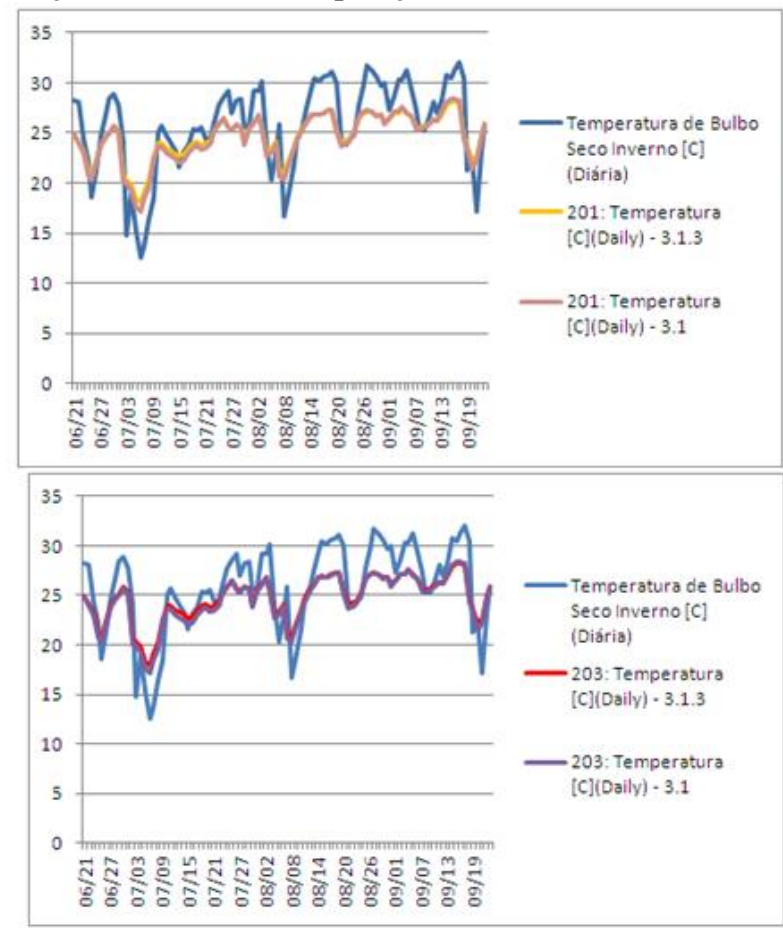

\section{Conclusões}

Este trabalho apresentou os resultados das simulações realizadas para avaliar o desempenho de HIS decorrente da "substituição" de materiais construtivos constituintes das envoltórias de edificações horizontais e verticais, bem como a influência das diferentes orientações dessas unidades habitacionais em relação ao sol, relacionado com o conforto térmico interno das edificações. A análise dos resultados para a edificação horizontal, ficou evidenciado que o simples fato da colocação de forro de madeira na cobertura da edificação e o assentamento dos tijolos da envoltória, na maior dimensão, melhoraram consideravelmente a temperatura interna da edificação e assim o conforto ambiental dentro da mesma. Quando simulada a mesma edificação, porém, com a consideração de materiais recomendados pela norma para a zona bioclimática 7 e com fachada orientada para o sudeste, alcançou-se menor temperatura interna nos meses de primavera (meses mais quentes do ano para a região em análise) e uma melhor conservação da temperatura interna nos meses mais frios, ou seja, meses de inverno.

Para a edificação vertical, tendo em vista que os materiais que constituem sua envoltória original são iguais aos da edificação horizontal analisada

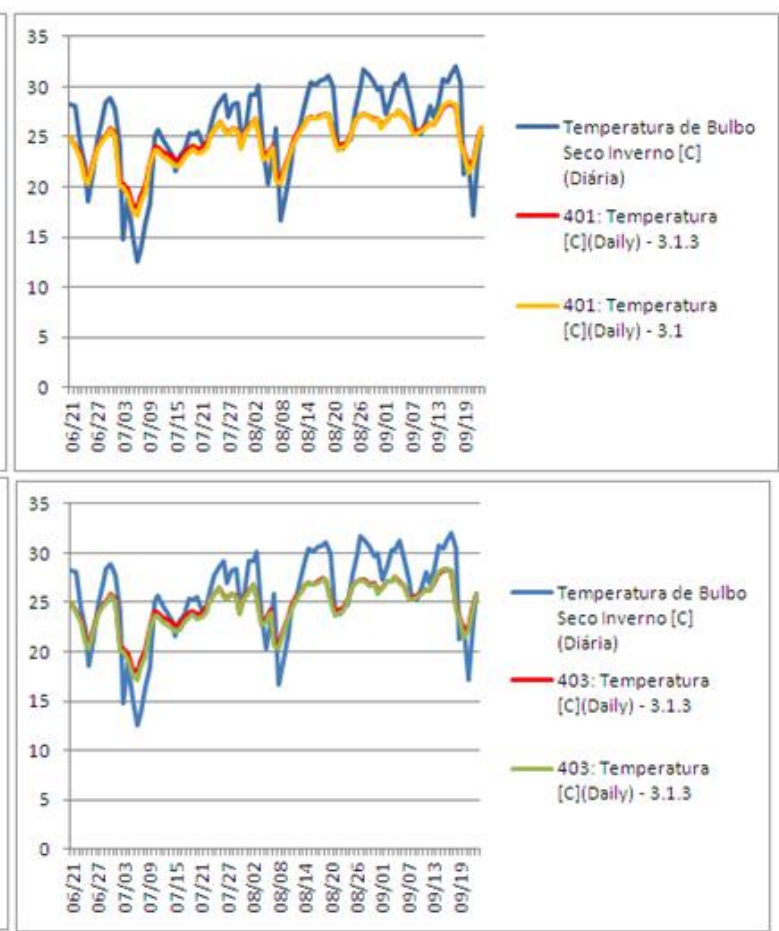

previamente, partiu - se da premissa de que, por possuírem características térmicas iguais, a composição que melhor serviu para a edificação horizontal também se aplicou para a edificação vertical.

A partir daí foram analisadas 4 apartamentos da edificação vertical, dois do segundo pavimento e dois do piso 4. De maneira a aferir o impacto do sol, em cada um dos andares, os apartamentos encontram-se em lados opostos, que respondem pela identificação: 201 e 401 203 e 403.

$\mathrm{Na}$ análise realizada para o prédio vertical, evidenciou-se, novamente, que o fato de assentar o tijolo do mesmo material existente na edificação em sua maior dimensão, providenciou um menor ganho térmico para o interior da edificação, estabelecendo um maior conforto térmico na primavera e inverno. A unidade de andar intermediário que é orientada para o leste em relação ao nascer do sol apresentou menor conforto térmico em seu interior do que a unidade intermediária orientada a oeste.

Para as unidades que compõem o último andar do prédio, devido à trajetória do sol e a inexistência de obstáculos naturais ou artificiais, as duas unidades recebem carga térmica igual, respondendo, portanto, de forma semelhante. Ressalta-se, que uma das unidades é orientada para o leste e a outra para o oeste. 
A diferença dos ganhos térmicos alcançados pelas edificações horizontais e verticais se devem, principalmente, a dois fatores principais: primeiro, não foi possível simular a troca da cobertura da edificação vertical uma vez que se trata de um edifício, diferente da edificação horizontal, fato que se traduz num ganho significativo em conforto térmico e por último, o edifício em análise se constitui apenas de 4 andares, não tendo assim grande influencia de ventos quando comparado a edifícios de 10 ou mais andares.

Vale ressaltar que devido ao fato de ambas as edificações utilizarem dos mesmos materiais construtivos os gráficos construídos se apresentaram muito próximos um do outro.

\section{Referências}

Eletrobrás/Procel; Procel Edifica; Laboratório de Eficiência Energética em Edificações LabEEE/UFSC. Manual de aplicação do RTQ-R. Sem data.

FROTA, A. B., \& SCHIFFER, S. R. Manual de Conforto Térmico. São Paulo: Studio Nobel $5^{\mathrm{a}}$ Ed. 2001.

HENSEN, J. L. M.; LAMBERTS, R.; NEGRAO, C. O. R. A view of energy and building performance simulation at the start of the millennium. Editorial. Energy and Building. Lausanne: Elsevier science, v. 34, p.853-855, 202.

MASCARÓ, L. R. Energia na edificação, estratégia para minimizar seu consumo. São Paulo, Projeto, 1986.

NBR - 15220. Desempenho térmico de edificações Parte 3: Zoneamento bioclimático brasileiro e diretrizes construtivas para habitações unifamiliares de interesse social. 2003

T.A.H. INATOMI (2008). Análise da eficiência energética do sistema de condicionamento de ar com distribuição pelo piso em ambiente de escritório, na cidade de São Paulo, utilizando o modelo computacional EnergyPlus. Dissertação
(Mestrado em engenharia). Departamento de engenharia da construção civil. Escola politécnica da Universidade de São Paulo, São Paulo, 2008. 